\title{
Ageing Characteristics of Sand Cast Al-Mg-Si (6063) Alloy
}

\author{
Aramide Fatai Olufe mi \\ Metallurgical and Materials Engineering Department, Federal University of Technology, Akure, Ondo State, Nigeria
}

\begin{abstract}
The effect of variation of ageing temperature and soaking time at the ageing temperature mechanical properties of a lu min iu 6063 alloy was investigated. Various samples of the alloy in the as-cast condition were produced, ho mogenized at $560^{\circ} \mathrm{C}$ held at the temperature for $2 \mathrm{hrs}$, and cooled in the furnace. They were solution treated at $440^{\circ} \mathrm{C}$ for 10 minutes and quench in water, aged at $/$ soaked for $125^{\circ} \mathrm{C} / 3 \mathrm{Hrs}, 125^{\circ} \mathrm{C} / 4 \mathrm{Hrs}, 125^{\circ} \mathrm{C} / 5 \mathrm{Hrs}, 175^{\circ} \mathrm{C} / 3 \mathrm{Hrs}, 175^{\circ} \mathrm{C} / 4 \mathrm{Hrs}, 175^{\circ} \mathrm{C} / 5 \mathrm{Hrs}, 200^{\circ} \mathrm{C}$ $/ 3 \mathrm{Hrs}, 200^{\circ} \mathrm{C} / 4 \mathrm{Hrs}, 200^{\circ} \mathrm{C} / 5 \mathrm{Hrs}$, and $225^{\circ} \mathrm{C} / 3 \mathrm{Hrs}, 225^{\circ} \mathrm{C} / 4 \mathrm{Hrs}$ and $225^{\circ} \mathrm{C} / 5 \mathrm{Hrs}$. Tensile and impact test were carried out on the alloy standard samples. It was observed that the Optimum tensile strength is observed in the sample aged at $175^{\circ} \mathrm{C}$ held for $5 \mathrm{hrs}$, optimum ductility is observed in sample aged at $125^{\circ} \mathrm{C}$, held for $4 \mathrm{hrs}$, Optimum toughness is observed in sample aged at $225^{\circ} \mathrm{C}$, held $5 \mathrm{hrs}$, closely followed by that of the sample aged at the same temperature, held for $3 \mathrm{hrs}$. From the economic point of view the optimu m para meter for obtaining a structural material of the optimu m co mbination of mechanical properties fro $\mathrm{m}$ the sample is ageing temperature of $225^{\circ} \mathrm{C}$ and soaking time of $3 \mathrm{hrs}$.
\end{abstract}

Keywords Ageing Temperature, Soaking Time, Intermetallic Phases, Solution Treatment

\section{Introduction}

Aluminium (6063) alloy is an alloy belonging to the $6 \mathrm{xxx}$ series. This alloy group contains silicon and magnesium in appropriate proportions to form magnesium silicide, thus making them heat-treatable. They possess good formability and corrosion resistance, with medium strength. Though the process of age hardening of aluminium alloys that contain $\mathrm{Mg}$ and Si was first discovered by Alfred Wilm in 1911,[1], this discovery led to searches for other aluminium alloy systems that would age harden[2]. These Al-Mg-Si alloys are the most widely used for the production of extruded sections. More than 80 percent of the aluminum alloys employed worldwide in the manufacturing of extruded sections belong to the 6xxx series[3]. In these alloys, $\mathrm{Mg}$ and $\mathrm{Si}$ combine to form the chemical compound $\mathrm{Mg}_{2} \mathrm{Si}$ (magnesium-silicide), the primary hardening phase[4].

Most of the added alloying elements to aluminum alloys are less soluble in the solid phase than in liquid, and then a gap between the liquidus and solidus will exist leading to the segregation of these alloying elements. This segregation is reduced by heating the ingots for an extended period close to the solidus temperature to homogenize the structure[8]. As the size of the cast product increases the chemical composition throughout the thickness will considerably

* Corresponding author:

fat2003net@yahoo.com (Aramide Fatai Olufemi)

Published online at http://journal.sapub.org/ijmee

Copyright (C) 2012 Scientific \& Academic Publishing. All Rights Reserved vary, (macrosegregation). This type of segregation is not much affected by heating but by controlling the manufacturing parameters of the ingot. For example, in the Direct-Chill casting process decreasing the ingot thickness, lowering the casting speed and maximizing the superheating temperature will greatly reduce this sort of segregation.

\section{Materials and Methods}

The materials used for this work are aluminium (6063) alloy obtained from 'A luminium Rolling Mill', Otta, Ogun State, Nigeria. The chemical composition of the aluminium alloy is given in Table 1 . in the as-cast condition.

Table 1. Chemical composition of the aluminium alloy sample

\begin{tabular}{|c|c|}
\hline Element & Average (Weight \%) \\
\hline $\mathrm{Mg}$ & 0.499 \\
\hline $\mathrm{Si}$ & 0.474 \\
\hline $\mathrm{Mn}$ & 0.025 \\
\hline $\mathrm{Cu}$ & 0.007 \\
\hline $\mathrm{Zn}$ & 0.004 \\
\hline $\mathrm{Ti}$ & 0.028 \\
\hline $\mathrm{Fe}$ & 0.243 \\
\hline $\mathrm{Be}$ & 0.004 \\
\hline $\mathrm{Pb}$ & 0.001 \\
\hline $\mathrm{Al}$ & 98.570 \\
\hline
\end{tabular}

Some quantities of the 6063 aluminium sample was melted in a crucible furnace and cast into cylindrical rods of $20 \mathrm{~mm}$ diameter and $200 \mathrm{~mm}$ length in a sand mould. Having solidified and allowed to cool, the cast rods were machined into standard tensile and impact strength specimen. 12 test 
samples were prepared for each of tensile and impact tests (24 samples in all); all the samples were homogenized at $560^{\circ} \mathrm{C}$ held at the temperature for $2 \mathrm{hrs}$, and cooled in the furnace, solution treated at $440^{\circ} \mathrm{C}$ for 10 minutes and quench in water $[8,9]$. The samples were divided into four groups of six samp les per group (each group to be aged at $125^{\circ} \mathrm{C} / 3 \mathrm{Hrs}$, $125^{\circ} \mathrm{C} / 4 \mathrm{Hrs}, 125^{\circ} \mathrm{C} / 5 \mathrm{Hrs}, 175^{\circ} \mathrm{C} / 3 \mathrm{Hrs}, 175^{\circ} \mathrm{C} / 4 \mathrm{Hrs}, 175^{\circ} \mathrm{C}$ $15 \mathrm{Hrs}, 200^{\circ} \mathrm{C} / 3 \mathrm{Hrs}, 200^{\circ} \mathrm{C} / 4 \mathrm{Hrs}, 200^{\circ} \mathrm{C} / 5 \mathrm{Hrs}$, and $225^{\circ} \mathrm{C}$ $13 \mathrm{Hrs}, 225^{\circ} \mathrm{C} / 4 \mathrm{Hrs}$ and $225^{\circ} \mathrm{C} / 5 \mathrm{Hrs}$ ), each group containing three test samples for each of the tests to be carried out.

\subsection{Tensile Testing}

The tensile tests were performed on various samples using Monsanto tensometer. The fracture load for each sample was noted as well as the diameter at the point of fracture and the final gauge length. The initial diameter and in itial gauge length for each sample was noted before uniaxial load. From the generated data the ultimate tensile strength and percentage elongation of each sample was calculated.

\subsection{Impact Test}

The impact tests were performed on various sample determine the impact strengths by the "V-notch method using the Honsfield Balance Impact Testing Machine. Prior to mounting on the machine, the test sample is notched to a depth of $2 \mathrm{~mm}$ with $\mathrm{v}$-shaped hand file. The notched test sample was then mounted on the impact-testing machine, which is the operated to apply a (constant) impact force on the test sample. The impact strength (the amount of impact energy the specimen absorbed before y ield ing) was then read off the calibrated scale on the impact testing machine.

\section{Results and Discussion}

Figure 1. depicts the effect of soaking time on the ultimate tensile strength of the samples; Figure 2. shows the effect of ageing temperature on the ultimate tensile strength of the samples; Figure 3. reveals the effect of ageing temperature on the ductility of the samples; Figure 4. depicts the effect of ageing temperature on the impact strength of the samples while in Figure 5. the effect of Soaking time on the Impact strength of the samples is clearly seen.

It could be seen from Figure 1. that the ultimate tensile strength (UTS) of the samples aged at $125^{\circ} \mathrm{C}$, increased slightly as the soaking time increases from 3 to 4 hours, thereafter further increase in the soaking time results in sharp reduction in the UTS. For those samples aged at $175^{\circ} \mathrm{C}$ and $200{ }^{\circ} \mathrm{C}$ the UTS remains constant and reduced slightly respectively with increment in the soaking time from 3 to 4 hour, further increase in the soaking time results in increase in the UTS. The UTS of those samples aged at $225^{\circ} \mathrm{C}$ decreased abruptly as the soaking time increased from 3 to 4 hours and thereafter increases sharply. This could be attributed to the fact that in silicon-containing aluminum alloys the most common phases are the $\alpha-\mathrm{Al}_{8} \mathrm{Fe}_{2} \mathrm{Si}$ and
$\beta-\mathrm{Al}_{5} \mathrm{FeSi}$ phases. Depending upon the alloy composition and solidification rate, one or both phases can be present in the microstructure. The $\beta-\mathrm{Al}_{5} \mathrm{FeSi}$ phase has needle-/ plate-like morphology and is considered detrimental to the ductility of the alloy. The $\alpha-\mathrm{Al}_{8} \mathrm{Fe}_{2} \mathrm{Si}$ phase is believed to be less harmful than the $\beta$-phase form as it has more desirable compacted Chinese script morphology. It is well known that at higher cooling rates, neutralization by the addition of trace elements such as $\mathrm{Mn}, \mathrm{Be}, \mathrm{Sr}$ can change the crystallization of the iron intermetallic to the Chinese script $\alpha$-phase form which improves the mechanical properties. Also, the presence of a small amount of beryllium produces a new $\mathrm{Be}-\mathrm{Fe}$ phase $\left(\mathrm{Al}_{8} \mathrm{Fe}_{2} \mathrm{SiBe}\right)$ having a Chinese script morphology or polygon shapes, which is different from the $\beta$-phase in the alloy samples $[10,11]$. From Figure 1., sample aged at $125^{\circ} \mathrm{C}$ contain some $\alpha-\mathrm{Al}_{8} \mathrm{Fe}_{2} \mathrm{Si}$ phase in the matrix of the alloy when it was soaked at the ageing temperature for between 3 and 4 hours, that explained the slight increase in the UTS with in this period. With further increase in the soaking time, all the $\alpha-\mathrm{Al}_{8} \mathrm{Fe}_{2} \mathrm{Si}$ phase in the matrix of the alloy were transformed into a mixture of $\beta-\mathrm{Al}_{5} \mathrm{FeSi}$ phase and $\mathrm{Mg}_{2} \mathrm{Si}$ precipitate, which accounts for the sharp reduction in UTS with further increase in the soaking time[10]. For those samples aged at $175^{\circ} \mathrm{C}$ and $200^{\circ} \mathrm{C}$ whose UTS remains constant and reduced slightly respectively with increment in the soaking time from 3 to 4 hour, this is due to the presence of a mixture of $\beta-\mathrm{Al}_{5} \mathrm{FeSi}$ phase and $\mathrm{Mg}_{2} \mathrm{Si}$ precipitate, within the soaking period at those temperatures. Increase in the soaking time to 5 hours resulted into transformation of the $\beta-\mathrm{Al}_{5} \mathrm{FeSi}$ phase and $\mathrm{Mg}_{2} \mathrm{Si}$ precipitate to a mixture of a new $\mathrm{Be}-\mathrm{Fe}$ phase $\left(\mathrm{Al}_{8} \mathrm{Fe}_{2} \mathrm{SiBe}\right)$ and $\mathrm{Mg}_{2} \mathrm{Si}$ precipitate; this accounts for the increase observed in the UTS at this condition. The UTS of those samples aged at $225^{\circ}$ wh ich decreased abruptly as the soaking time increased from 3 to 4 hours and thereafter increases sharply, can be exp lained by the explanation given for the behaviour of the samp les aged at $200^{\circ} \mathrm{C}$, but because of higher ageing temperature the a mount of $\beta-\mathrm{Al}_{5} \mathrm{FeSi}$ phase is more which later transformed to Be-Fe phase as the soaking time is increased to 5 hours [12].

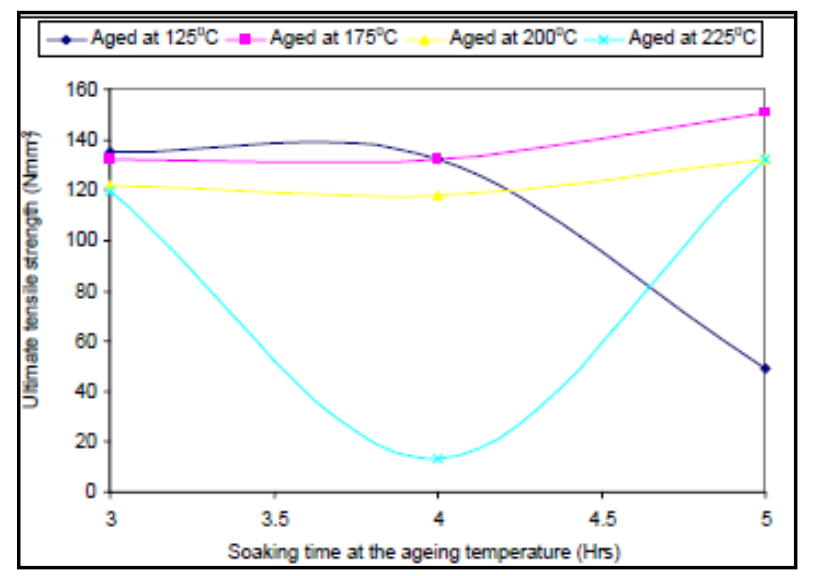

Figure 1. Effect of soaking time on the ult imate tensile strength of the samples 


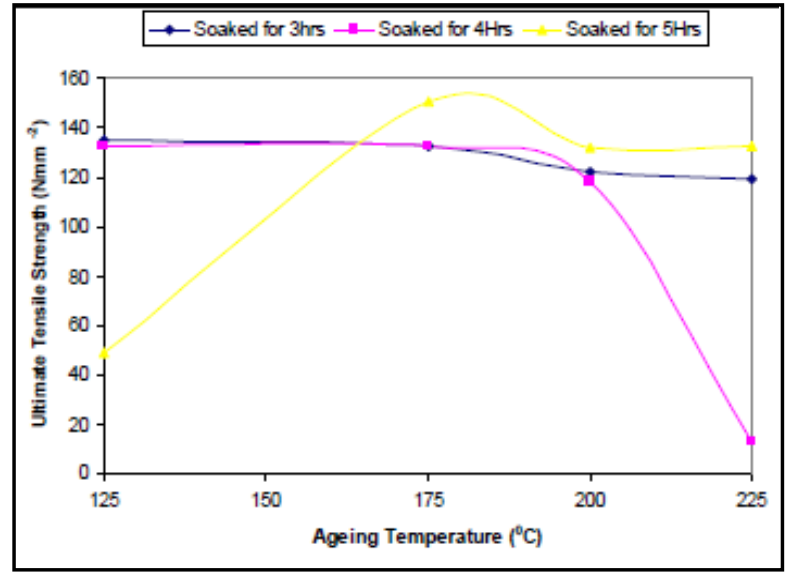

Figure 2. Effect of ageing temperature on the ult imate tensile strength of the samples

Furthermore, in Figure 2. for samples soaked at the different ageing temperature for 3 and 4 hours, the UTS is almost constant (and the same) as the ageing temperature increased from $125^{\circ} \mathrm{C}$ to $175^{\circ} \mathrm{C}$, thereafter, the UTS reduced (though at different rates) with increase in the ageing temperature. For samples soaked at the different ageing temperature for 5 hours, it is obvious that the UTS increases with increase in the ageing temperature, the maximum UTS is attained at around $175^{\circ} \mathrm{C}$, thereafter, increase in the ageing temperature results in reduction in the UTS of the samples. Moreover, in Figure 3. the effects of various ageing temperature on the ductility of the alloy samples is clearly seen. As expected, increased hardness will defin itely lead to reduced ductility,[13]: The ductility of the alloy samples soaked for 3 and 4 hours at various ageing temperature reduces with increasing ageing temperature (though at different rates), while the ductility of the samples soaked for 5 hours first increases with the ageing temperature up to about $200^{\circ}$ before reduction in the ductility follows further increase in the ageing temperature.

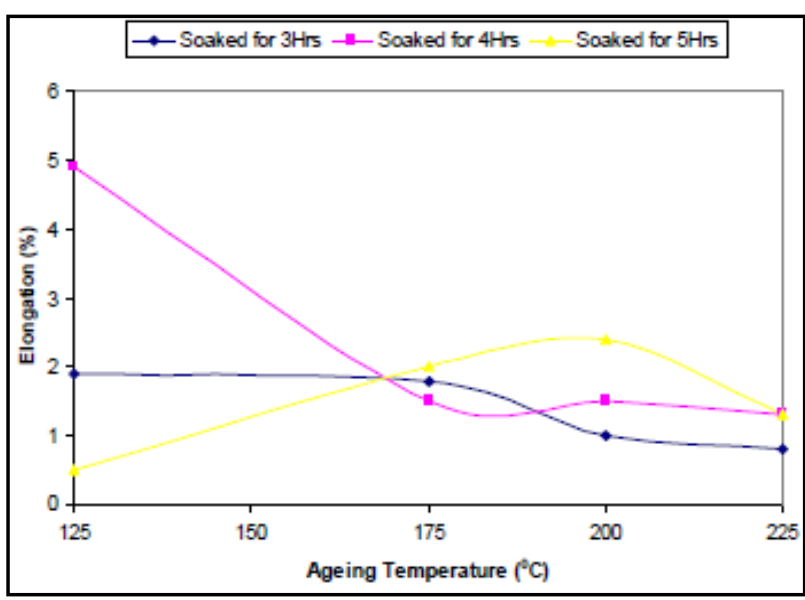

Figure 3. Effect of ageing temperature on the ductility of the samples

Moreover, Figures 4. and 5. relate the effects of ageing temperature and soaking time at the ageing temperature respectively on the impact strength (absorbed energy) of the alloy samples. It could be seen that for samples soaked for 3 and 5 hours, the impact strength increases with the ageing temperature; this is expected the stiffness of the samples increases with the ageing temperature as explained in Figure 3. above. For those samples soaked at the various ageing temperature for 4 hours, the impact strength reduces with increase in age ing temperature. This is also clear in Figure 5.; this is fully explained by the explanations offered on Figure 1. .

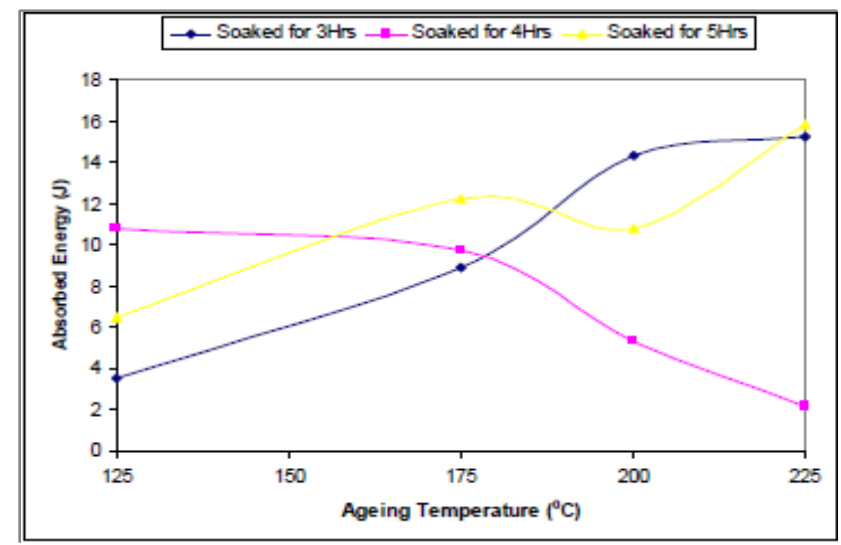

Figure 4. Effect of ageing temperature on the impact strength of the samples

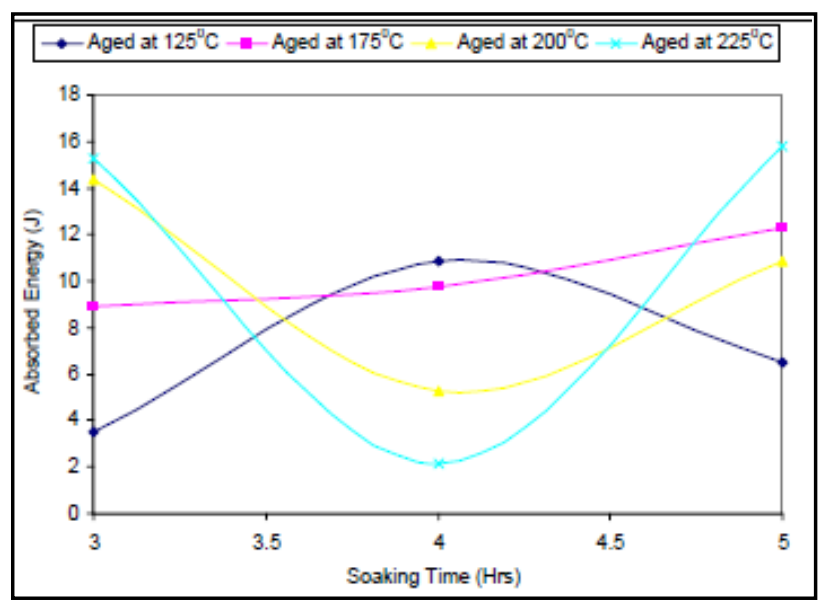

Figure 5. Effect of Soaking time on the Impact strength of the samples

\section{Conclusions}

From the discussion thus far, it can be concluded that:

- Optimum tensile strength is observed in the sample aged at $175^{\circ} \mathrm{C}$ held for 5 hrs.

- Optimum ductility is observed in sample aged at $125^{\circ} \mathrm{C}$, held for 4 hrs.

- Optimum toughness is observed in sample aged at $225^{\circ} \mathrm{C}$, held 5 hrs, closely followed by that of the samp le aged at the same temperature, held for $3 \mathrm{hrs}$.

- From the economic point of view the optimum parameter for obtaining a structural material of the optimum combination of mechanical properties from the sample is ageing temperature of $225^{\circ} \mathrm{C}$ and soaking time of $3 \mathrm{hrs}$.

\section{ACKNOWLEDGEMENTS}


The authors would like to acknowledge the assistance rendered by $\mathrm{Mr}$ Alo F.I., Mr Aminu, Mr Omolayo, $\mathrm{Mr}$ Olaoye and Mr Solanke, (all of the Department of Materials Science and Engineering, O.A.U., Ile-Ife) during the bench work of this research.

\section{REFERENCES}

[1] Wilm, A. Metallurgie, 8, 223, 650, Germany, 1911

[2] Staley, J.T. Treatise on Materials Science and Technology, vol.31, Alloys: Contemporary Research and Applications, eds. A.K. Vasudevan and R.D. Doherty, 3, 1989

[3] Marchive, D., (1983); Light Met. Age, pp: 6-10.

[4] Traenker, F.O., Proc. 2nd Intl. Aluminum Extrusion Technol. Sem., $1: 339-347,1977$

[5] Marker, G.L. and J. Kruger, Intl. Mater. Rev., 38: 138-153, 1993 in G. Al-Marahleh Effect of Heat Treatment Parameters on Distribution and Volume Fraction of $\mathrm{Mg}_{2} \mathrm{Si}$ in the Structural Al 6063 Alloy American Journal of Applied Sciences 3 (5): 1819-1823, 2006

[6] Lee, S.H., Soho, K.S., Park, I.M. and Cho, K.M., Met. Mater., 1: 37-46, 1995 in G. Al-Marahleh Effect of Heat Treatment Parameters on Distribution and Volume Fraction of $\mathrm{Mg}_{2} \mathrm{Si}$ in the Structural Al 6063 Alloy American Journal of Applied Sciences 3 (5): 1819-1823, 2006
[7] Mordike, B.L. and T. Ebert, Mater. Sci. Eng., A302: 37-45, 2001 in Atsushi Shibayama, Yoshihiro Terada, Yoshinori Murata and Masahiko Morinaga Creep Behavior of Hypoeutectic Mg-Ca Binary Alloys, Materials Transactions, Vol. 51, No. 12 (2010) pp. 2284 to 2288 [doi:10.2320/ matertrans.M2010201]

[8] Davis, J.R., (1993); Aluminum and Aluminum Alloys. ASM specially Handbook, ASM International, Materials Park, $\mathrm{OH}$, pp 784.

[9] ASM Handbook, Heat Treating. ASM International, 4: 841-879, 1997

[10] Mulazmoglu, M.H., Zaluska, A., Gruzleski, J.E. and Paray, F., "Electron Microscope Study of Al-Fe-Si Intermetallies in 6201 Aluminum Alloy", Metallurgical and Materials Transactions A, vol. 27 A, p.929-935, 1996

[11] Gruzleski, J.E., Paray, F., Shabestari, S.G. and Mulazimoglu, M.H., "Applications of Strontium in Cast and Wrought Aluminum Alloys", A113 le Magazine de l'Aluminium, vol. 2, no. 1 , p. 23-33, 1996

[12] Marioara, C.D., Andersen, S.J., Jansen, J. and Zandbergen, H.W., The influence of temperature and storage time at RT on nucleation of the $\beta$ ", phase in a $6082 \mathrm{Al}-\mathrm{Mg}$-Si alloy, Acta Materialia 51, 789- 796, 2003

[13] Callister, W.D. Materials Science and Engineering An Introduction. John Wiley and sons, Inc., N, 2000. 